\title{
Ingested interferon $\alpha$ suppresses Type I diabetes in non-obese diabetic mice
}

\author{
S.A. Brod ${ }^{1}$, M. Malone ${ }^{1}$, S. Darcan ${ }^{2}$, M. Papolla ${ }^{4}$, L. Nelson ${ }^{3}$ \\ ${ }^{1}$ Department of Neurology, University of Texas-Houston, Houston, Texas, USA \\ ${ }^{2}$ Division of Paediatric Endocrinology, Department of Paediatrics, University of Texas-Houston, Houston, Texas, USA \\ ${ }^{3}$ Graduate School of Biomedical Sciences, University of Texas-Houston, Houston, Texas, USA \\ ${ }^{4}$ Department of Pathology, University of South Alabama Medical Centre, Mobile, Alabama, USA
}

Summary Type I diabetes mellitus is a chronic disorder that results from autoimmune destruction of the insulin-producing pancreatic beta cell. The nonobese diabetic mouse is a model of the human autoimmune disease Type I diabetes [1-3]. We have previously shown that ingested type 1 interferon inhibits chronic relapsing experimental autoimmune encephalomyelitis and the adoptive transfer of experimental autoimmune encephalomyelites by $\mathrm{T}$ cells, and decreases both antigen-specific and mitogen-induced pro-inflammatory cytokine secretion in this disorder. We therefore tried to determine whether ingested murine interferon $\alpha$ inhibits insulinitis and suppresses Type I diabetes mellitus in non-obese diabetic mice. Murine interferon $\alpha$, given daily, decreased islet inflammation and suppressed diabetes. It increased the concanavalin $\mathrm{A}$ and ionomycin plus myristic acid palmitic ester-induced production of in- terleukin 4 and 10 and interferon $\gamma$-secretion in spleen cells from treated mice. Adoptive transfer of unstimulated splenocytes secreting interleukin 4 and interleukin 10 from fed interferon $\alpha$ donors suppressed spontaneous diabetes mellitus in recipients. The protective effect of adoptively transferred unstimulated splenocytes shows the presence of ingested interferon $\alpha$-activated regulatory splenic cell populations that may work via increased interleukin 4 or interleukin 10 production. Ingested interferon $\alpha$ administered during vulnerable periods in at-risk populations may potentially provide a continuous, convenient, non-toxic and effective treatment for Type I diabetes. [Diabetologia (1998) 41: 1227-1232]

Keywords Non-obese diabetic mouse, ingested interferon $\alpha$, interleukin 4 , interleukin 10 , adoptive transfer
Many key features of human Type I diabetes are reflected in the non-obese diabetic (NOD) mouse model. These include the development of insulitis, with infiltration of lymphocytes that are selectively cytotoxic to the insulin producing beta cells into the pancreatic islets of Langerhans, the dependence of disease pathogenesis by T cells, and the transmission of

Received: 14 April 1998 and in revised form: 11 May 1998

Corresponding author: Dr. S. A. Brod, University of Texas Health Science Center at Houston, Department of Neurology, 7.044, P. O. Box 20708, Houston, Tx 77225, USA

Abbreviations: EAE, experimental autoimmune enecephalomyelities; NOD, non-obese diabetic; IL, interleukin; IFN, interferon; ConA, concavalan A; PMA, myristic acid palmitic ester; $\mathrm{TNF}$, tumor necrosis factor
Type I diabetes by haematopoietic cells in bone marrow [1-5].

Experimental autoimmune encephalomyelitis (EAE) is an animal model for the presumed autoimmune disease multiple sclerosis. We have previously shown that ingested type 1 interferon (IFN) inhibits chronic relapsing EAE, inhibits the adoptive transfer of EAE by $T$ cells, decreases both antigen-specific and mitogen-induced pro-inflammatory cytokine secretion and decreases serum soluble intercellular adhesion molecule 1 (sICAM-1) levels, a marker for subclinical disease activity, in multiple sclerosis without the absorption of ingested IFN [6-8].

The NOD mouse [9-11] model is mechanistically analogous to the EAE animal model because both are presumed to be mediated by a T cell subset, and depend on restriction elements and inflammatory cy- 
tokines for disease expression. Both Type I diabetes and EAE can be induced by T cells, primarily one of the two types of helper T cells - T helper cells type 1, which produce pro-inflammatory cytokines such as IFN- $\gamma$ [12]. Administration or upregulation of the type $2 \mathrm{~T}$ helper-associated cytokines interleukin (IL-4) and IL-10 can ameliorate autoimmune disease [13]. Because multiple sclerosis and Type I diabetes share several features of immunopathogenesis, we decided to determine whether murine ingested IFN- $\alpha$ inhibits insulitis and suppress diabetes in NOD mice.

\section{Material and methods}

Animals and feeding regimen. Female NOD mice (NOD MrkTacfBR) were obtained from Taconic Farms at 8 weeks of age. Feeding with mock IFN $(n=10)$ or $10 \mathrm{U}$ murine IFN$\alpha(n=10)$ every other day or daily was started at 9 weeks. The mice were maintained and fed under specific pathogenfree conditions in microisolators, and were handled under negative pressure sterile hoods. Surveillance mice were maintained with experimental mice and were examined regularly for routine murine pathogens.

Mice were followed up after initiation of feeding by weekly blood glucose determination (Life Scan One Touch II, Johnson \& Johnson, USA) beginning at week 10. Animals were considered diabetic if two consecutive blood glucose determinations were $>11.1 \mathrm{mmol} / \mathrm{l}$. Spontaneous diabetes (blood sugar $>11.1 \mathrm{mmol} / \mathrm{l}$ ) occurs in $50 \%$ female NOD mice by age 19 weeks in our facility.

Ten units of mIFN- $\alpha$ (Cytimmune mouse IFN- $\alpha, 4.0 \times 10^{5}$ IRU/ml, Lee Biomolecular Research, Inc., San Diego, Calif., USA), or mock murine IFN- $\alpha$ (Cytimmune $<2$ IRU/ml, Lee Biomolecular Research, Inc., San Diego, Calif., USA) was administered directly to the stomach and proximal small intestine using a $2.5 \mathrm{~cm}$ syringe fitted with a 22-24 gauge ball point needle (Thomas Scientific, Swedesboro, N.J., USA) every other day or daily to NOD mice beginning at age nine weeks. IFN$\alpha$ was delivered directly to the distal oesophagus, stomach and proximal small intestine (as determined experimentally by injecting Evans' blue during routine feeding and subsequent sacrifice). An equal number of control animals were fed mock mIFN. We used mock murine IFN control. This preparation is identical to the IFN preparation, which is purified of virus, except that the mock control is not induced with Newcastle disease virus (according to Lee Biomolecular). Therefore the mock murine preparation has whatever normal cell components are contained in the Newcastle disease virusinduced preparation. Disease course was plotted as KaplanMeier curve with the y axis denoting the percentage of mice remaining non-diabetic.

Measurement of cytokine secretion (experiment 1). Splenocytes from individual non-diabetic untreated $(n=4)$ or non-diabetic treated mice $(n=9)$ were stimulated with concananalin A (Con A) or ionomycin plus myristic acid palmitic ester (PMA) mitogens. Because ingested type I IFNs are systemic immunomodulators, and mitogen stimulation reflects both the systemic and target-organ immune response in treated mice $[6,7,14]$, Con A and ionomycin + PMA were used. Individual spleens were removed under aseptic conditions, single cell suspensions were prepared, and red cell lysis was performed by adding 2-3 ml sterile water to single cells for $5 \mathrm{~s}$, and, once the solution had become transparent, adding serum-free media to a $50 \mathrm{ml}$ tube. Splenocytes were stimulated with Con A at a final concentration of $2.5 \mu \mathrm{g} / \mathrm{ml}$ (Sigma Chemical Co., St Louis, Mo., USA) or ionomycin at $100 \mathrm{ng} / \mathrm{ml}$ (Calbiochem, La Jolla, Calif., USA) in combination with PMA at $1 \mathrm{ng} / \mathrm{ml}$ (Sigma Chemical Co., St. Louis, Mo., USA) for $48 \mathrm{~h}$ in serum free medium (AIM-V medium, Gibco BRL, Grand Island, NY) with $2 \times 10^{5}$ cells $/ 200 \mu \mathrm{l}$ in triplicate in 96 well U-bottomed plates in a humidified $5 \% \mathrm{CO}_{2} / 95 \%$ air incubator at $37^{\circ} \mathrm{C}$. Murine IL-1, IL-2, IL-4, IL-6, IL-10, IFN- $\gamma$ kits (Biosource International, Camarillo, Calif., USA), TNF- $\alpha$ and transforming growth factor $\beta$ (TGF- $\beta$ ) ELISA kits (Genzyme, Cambridge, Mass., USA) were used. Results were given as mean \pm SEM of individual samples from mice fed mock IFN or mice fed with $10 \mathrm{mIFN}-\alpha$ and were expressed as $\mathrm{pg} / \mathrm{ml}$.

Islet histology (experiment 2). Mice were killed after reaching end point (week 24). Each pancreas from individual non-diabetic untreated $(n=4)$ and non-diabetic treated mice $(n=9)$ was harvested, fixed in $10 \%$ formalin, embedding in paraffin, sectioned at $10 \mu$, and stained with haematoxylin and eosin. A pathologist, blinded to the treatment groups, scored the pancreas. Coded slides were read by light microscopy. Islet inflammation (insulitis) was graded 0 to 4 , according to the extent of peri-islet and intra-islet infiltration by mononuclear cells as follows: $0=$ none; 1 = peri-islet leucocytes without islet infiltration; $2=<25 \%$ islet area infiltrated by leucocytes; $3=25-75 \%$ islet area infiltrated; and $4=>75 \%$ islet area infiltrated. A mean insulitis score was calculated for each pancreas by dividing the sum of the insulitis score for individual islets by the number of islets examined ( $>40 /$ pancreas) [15].

Adoptive transfer (experiment 3). After 15 weeks of ingested mock IFN or $10 \mathrm{U}$ mIFN- $\alpha$ treatment (experiment number 2 above), spleens from non-diabetic donors were removed aseptically from donors, and single cell suspensions were prepared. Cells were collected, washed twice in phosphate buffered saline, and viability was determined by standard Trypan blue exclusion. Thirty million viable unstimulated lymphocytes in $1 \mathrm{ml}$ Dulbecco's PBS were injected introperitoneally into 8 week old NOD recipients from mock fed non-diabetic donors or IFN- $\alpha$ fed donors and were followed for 24 weeks.

Statistics. Statistical analysis was performed using one-tailed Student's t test or log rank (Cox method) (SyStat 7.0.1, SPSS Inc).

\section{Results}

In the first set of experiments, 20 female NOD mice were mock treated $(n=10)$ or treated with $10 \mathrm{U}$ mIFN- $\alpha(n=10)$ every other day starting at age 9 weeks. Mice treated with $\mathrm{mIFN}-\alpha$ showed a delayed onset of Type I diabetes and a decreased frequency of diabetes compared with mock treated mice, but this did not reach statistical significance (Fig.1).

Because daily administration of type I IFN protects against acute EAE in the Lewis rat model, we examined whether feeding every day would provide more protection against diabetes. In a second set of experiments, 20 female NOD mice were mock treated $(n=10)$ or treated with $10 \mathrm{U}$ mIFN- $\alpha(n=10)$ every day starting at age 9 weeks. Mice ingesting 


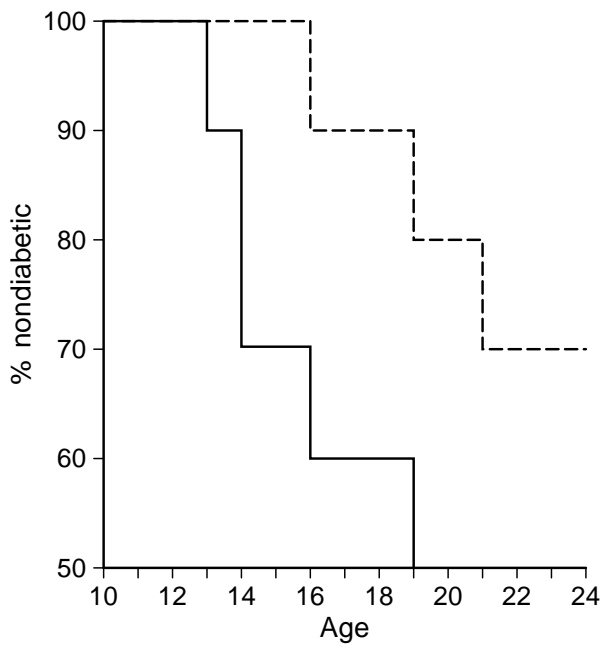

Fig. 1. Ingestion of mIFN- $\alpha$ on alternate days from age 9 weeks reduced the incidence of Type I diabetes in NOD mice. Twenty female NOD mice were fed mock IFN $(n=10)$ or $10 \mathrm{U}$ mIFN- $\alpha(n=10)$ three times per week starting at 9 weeks and followed with weekly blood glucose determination beginning at week 10. Data on time to overt diabetes in each group were analysed by Kaplan Meier survival curve showing the percentage remaining non-diabetic in relation to age. Mice fed IFN- $\alpha$ (dotted line) showed a delayed onset of diabetes and fewer of them became diabetic than the mock treated (solid line) animals

mIFN- $\alpha$ showed a more significant delay in the onset of Type I diabetes and a reduced frequency of diabetes $(p<0.014$ by log rank test) (Fig. 2). There was also a significant decrease in islet inflammation in this experiment $(3.0 \pm 0.4$ untreated mice vs $2.1 \pm 0.3$ treated, mice, $p<0.05)$.

Because mitogen stimulation reflects non-antigen and antigen-specific responses [6, 7, 14], we compared the cytokine profiles of Con A and ionomycin/ PMA stimulated spleen cells in mock treated and oral mIFN- $\alpha$ treated mice. Whole splenocytes from non-diabetic mice from the second set of experiments were stimulated with Con A or ionomycin/PMA, and IL-1, IL-2, IL-4, IL-6, IL-10, IFN- $\gamma$, TNF- $\alpha$ and TGF$\beta$ were measured. Splenocytes from IFN- $\alpha$ treated mice showed increased production of IL-2, IL-4, IL6 , IL-10 and IFN- $\gamma$ after Con A stimulation, and increased production of IL-4, IL-10 and IFN- $\gamma$ after ionomycin/PMA stimulation (Fig. 3). However, both Con $\mathrm{A}$ and ionomycin/PMA activation increased the production of proinflammatory IFN- $\gamma$ and the counter-regulatory anti-inflammatory IL-4 and IL-10 cytokines. There were no significant changes in Con A or ionomycin/PMA stimulated TNF- $\alpha$, IL-1 and TGF- $\beta$ secretion (data not shown).

To determine whether the protective effect of the ingested IFN- $\alpha$ was transferred to spleen cell populations, we next examined whether adoptive transfer of splenocytes from mIFN- $\alpha$ fed donors could protect against diabetes. NOD mice from experiment 2

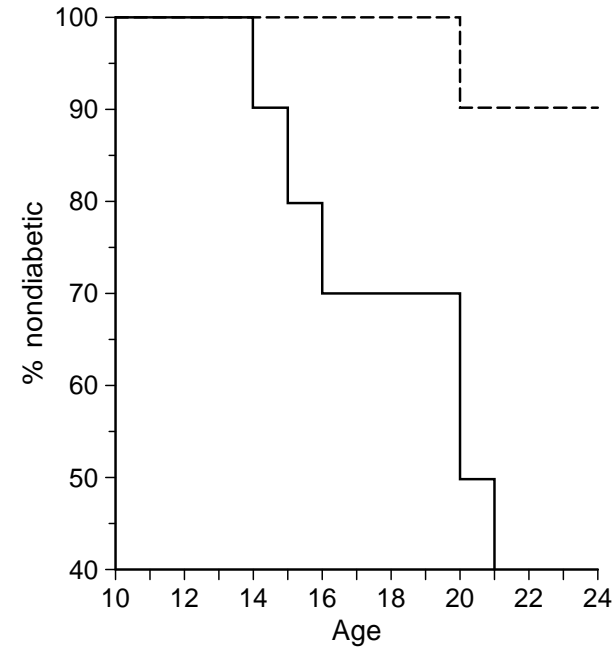

Fig. 2. Daily ingestion of mIFN- $\alpha$ from age 9 weeks enhanced the suppression of Type I diabetes in NOD mice. Twenty female NOD mice were fed mock IFN $(n=10)$ or $10 \mathrm{U}$ mIFN- $\alpha$ $(n=10)$ daily from age 9 weeks. Mice were followed and data were analysed as described in Fig. 1. Mice fed IFN- $\alpha$ (dotted line) showed significantly greater delayed onset of Type I diabetes and fewer became diabetic than the mock treated (solid line) mice ( $p<0.014$ by log rank test). A representative experiment from two individual experiments is shown.

above, fed mock IFN or mIFN- $\alpha$ every day for 14 weeks, were used as donors. After 14 weeks of feeding, spleens were harvested from non-diabetic mice in both groups and single cell splenocytes were isolated. Unstimulated lymphocytes were injected intraperitoneally into 8 week old NOD recipients from mock fed non-diabetic donors $(n=8)$ or IFN- $\alpha$ fed donors $(n=12)$. Mice were followed up for 40 weeks thereafter. Development of Type I diabetes was delayed in $50 \%$ of mice receiving cells from IFN- $\alpha$ fed donors (6/12) (Fig.4) compared with mice receiving cells from mock fed donors (8/8), all of which became diabetic at 24 weeks $(p<0.038$ by log rank test).

\section{Discussion}

Our data show that primary dysfunction of islets is prevented by treatment with ingested IFN- $\alpha$, in spite of upregulation of IFN- $\gamma$. The ratio of counter-regulatory anti-inflammatory IL-4 or IL-10 to IFN- $\gamma$ may be critically important in determining the balance between disease and protection in the NOD mouse [16]. Untreated non-diabetic mice produced no IL-4, but non-diabetic mice ingesting IFN- $\alpha$ produced $31 \mathrm{pg} /$ $\mathrm{ml}$ of IL-4 after Con A stimulation.

Type $2 \mathrm{~T}$ helper-like cytokines can protect against the development of Type I diabetes in the NOD mouse. IL-4 is a potential counter-regulatory anti-inflammatory cytokine to type $1 \mathrm{~T}$ helper cells [13], and can inhibit the actions of IFN- $\gamma$ [17-20]. The in vivo administration of recombinant IL-4 to predia- 

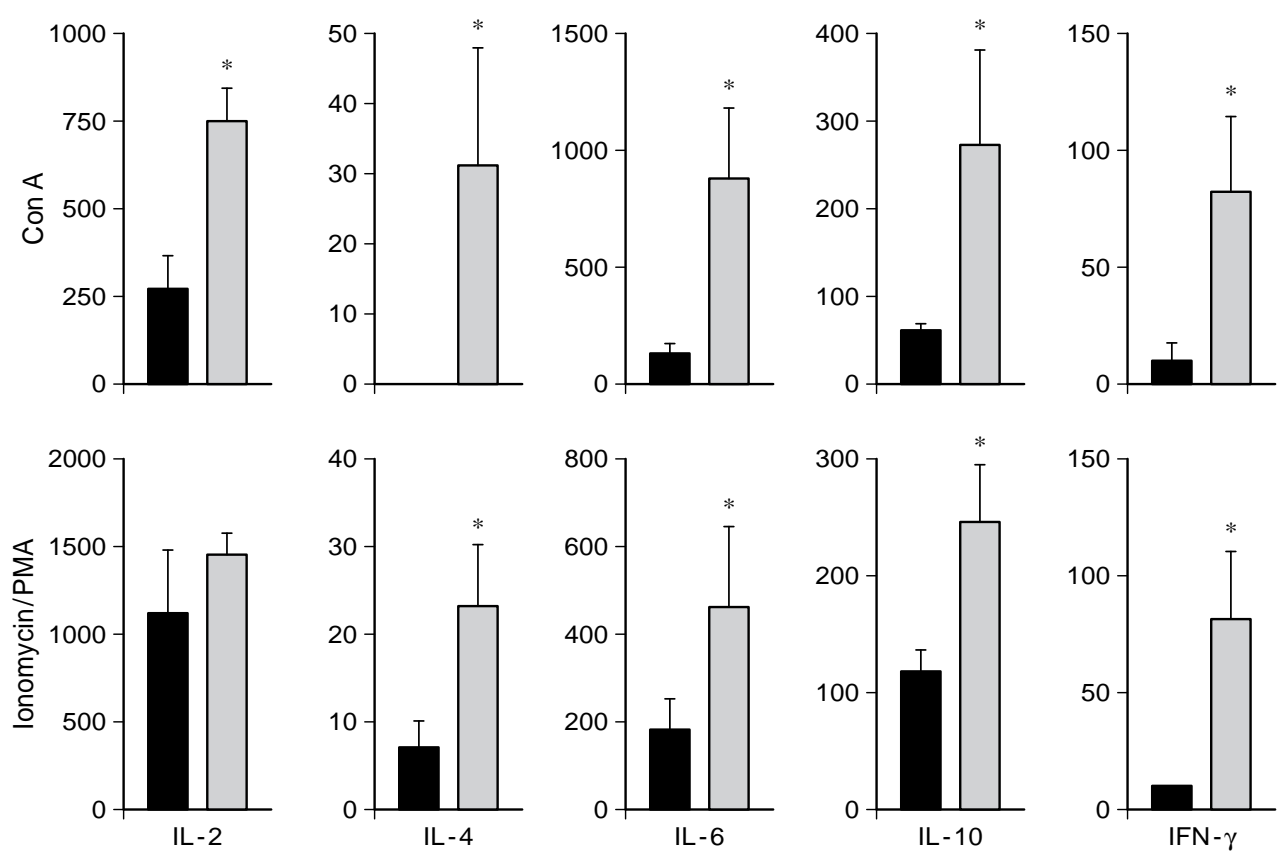

Fig.3. Ingested mIFN- $\alpha$ increases the mitogen-induced production of IL-4, IL-10 and IFN- $\gamma$ in spleen cells. Splenocytes from individual non-diabetic mock treated $(n=4)$ or non-diabetic treated mice $(n=9)$ were stimulated with Con A or ionomycin + PMA. Individual data correspond to mice ingesting 10 $\mathrm{U}$ mIFN- $\alpha$ (white bars) or animals ingesting mock IFN (black bars). Results are expressed as pg/ml, mean \pm SEM. *Designates a significant difference between treated and mock treated animals. Con A: untreated vs treated mice: IL-2, $p<0.025$ IL-4, $p<0.05$; IL-6, $p<0.02$; IL-10, $p<0.04$; IFN- $\gamma, p<0.05$. Ionomycin + PMA: untreated vs treated mice: IL-2, $p<0.21$; IL-4, $p<0.05$; IL-6, $p<0.07$; IL-10, $p<0.015$; IFN- $\gamma, p<0.03$. Results are from the combined results of the two experiments outlined in Fig. 2 above

betic NOD mice protects them from diabetes [21]. Transgenic IL-4 NOD mice were protected from insulitis and diabetes, a significantly higher ratio of mitogen-induced IFN- $\gamma /$ IL-4 was found in diabetic NOD mice but not in age-matched non-diabetic NOD mice and treatment of isologous islet transplants with the Type $2 \mathrm{~T}$ helper cell-associated cytokines IL-4 and IL-10 in spontaneously diabetic nonobese recipients restored immediate function of the grafts [16, 22, 23]. Induction of functional tolerance to islet antigens is indicated by the failure of diabetogenic spleen cells to induce diabetes in transgenic NOD-IL-4 recipients. IL-4 can prevent the development of autoimmunity and destructive autoreactivity in the NOD mouse [23].

Other type $2 \mathrm{~T}$ helper cell-like cytokines can modulate the onset of diabetes. Daily subcutaneous administration of IL-10 (a potent known inhibitor of IFN- $\gamma$ production by type $1 \mathrm{~T}$ helper cells) to 9 and 10 week old NOD mice was shown to delay the onset of disease, significantly reduce the incidence of dia- betes and reduce the severity of insulitis, to prevent cellular infiltration of islet cells and promote normal insulin production by beta cells [24]. Administration of non-cytolytic murine IL-10/Fc fusion protein from 5 to 25 weeks of age completely prevented diabetes in the NOD model. Immunohistochemistry studies showed that IL-10/Fc treatment promoted expression of IL-4 and IL-10, type 2 T helper cytokines, by isletinfiltrating leucocytes [25]. Primary non-function of islet grafts is prevented by treating the recipients with a combination of IL-4 and IL-10, via downregulation of type $1 \mathrm{~T}$ helper cytokines [22].

Our data also show that the adoptive transfer of splenocytes from donors who have ingested IFN- $\alpha$ and produced counter-regulatory anti-inflammatory IL-4 or IL-10 protects against diabetes in NOD recipients. Mice receiving unstimulated splenocytes from mock IFN ingesting donors had a faster onset of diabetes than the mock treated mice in experiments 1 and 2 . The protective effect of adoptively transferred unstimulated splenocytes from donors that have taken IFN- $\alpha$ shows the presence of ingested IFN- $\alpha$-activated regulatory splenic cell populations that may work via increased IL-4 or IL-10 production.

In contrast, intra-islet IFN- $\gamma$ (type $1 \mathrm{~T}$ helper celllike) has a diabetes-promoting role, while IL-4 and IL-10 (type $2 \mathrm{~T}$ helper cell-like) protect against diabetes [26, 27]. During a later phase of insulitis, there is a characteristic type $1 \mathrm{~T}$ helper cytokine profile, with production of IFN- $\gamma$ occurring after stimulation [28]. IFN- $\gamma$ has been detected in lymphocytes infiltrating the islets of humans with recent onset Type I diabetes. IFN- $\gamma$ transgenic mice develop Type I diabetes, and antibodies against IFN- $\gamma$ protect against diabetes development in NOD mice and $\mathrm{BB}$ rats [29-34]. However, IFN- $\gamma$ may itself be immunosup- 


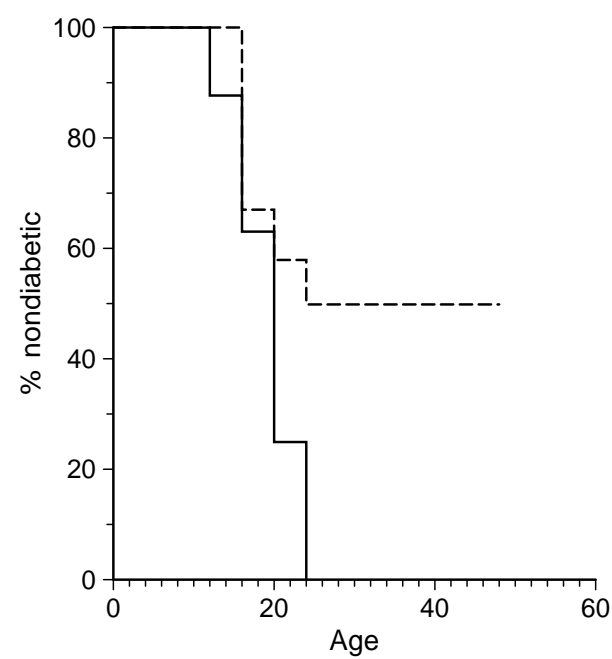

Fig.4. Adoptive transfer of unstimulated splenocytes from $\mathrm{mIFN}-\alpha$ fed donors suppressed spontaneous diabetes in recipients. Donor NOD mice were fed mock IFN or mIFN- $\alpha$ daily for 14 weeks. After 14 weeks, spleens were harvested from non-diabetic mice in both groups and single cell lymphocytes were isolated. Thirty million unstimulated lymphocytes were injected intraperitoneally into 8 week old NOD recipients from mock fed non-diabetic donors $(n=8)$ or IFN- $\alpha$ fed donors $(n=12)$. Mice were followed for 40 weeks thereafter. Mice given cells from IFN- $\alpha$ fed donors (dotted line) showed significantly greater delayed onset of Type I diabetes than mice given cells from mock fed donors (solid line) $(p<0.038$ by log rank test)

pressive under certain conditions. Human CD8 + T cells activated via the autologous mixed lymphocyte reaction (AMLR) suppress CD3 mediated proliferation of autologous $\mathrm{T}$ cells through IFN- $\gamma$ secretion [35]. IFN- $\gamma$ can also mediate suppression by antigenspecific T suppressor clones [36].

IFN- $\alpha$ has been detected in beta cells of animals and people with recent onset Type I diabetes [37, 38]. Islet beta cell transgenic expression of IFN- $\alpha$ in mice elicits an immune mediated destruction of beta cells, and may recruit immune system cells to damage IFN- $\alpha$-producing cells [39]. However, there is no evidence that the biologic effect of ingested IFN- $\alpha$ observed is dependent on its gastrointestinal absorption. Pharmacokinetics of IFNs delivered by various routes have shown that orally administered IFNs failed to appear in the bloodstream [40-46]. We have recently shown increased relative type I IFN-induced Mx mRNA levels, a type 1 IFN-specific induced message, using semi-quantitative reverse transcriptase polymer chain reaction on splenocytes after ingestion of mIFN- $\alpha$ (unpublished data). IFN-activated lymphocytes, by virtue of their ability to circulate through the body from the gut associated lymphoid system, have the potential to transfer their biological activities widely in the absence of circulating cytokines after contacting IFN in the gut associated lymphoid system [43, 47-49].
The natural history of the development of Type I diabetes includes a presymptomatic stage between the occurrence of insulitis and the onset of symptomatic hyperglycaemia, and provides a broad therapeutic window for intervention between $\mathrm{T}$ cell islet infiltration and beta cell numbers falling below that required to maintain normoglycaemia [50]. Ingested IFN- $\alpha$ may be an ideal treatment for Type I diabetes before or immediately after diagnosis. Ingested IFN$\alpha$ may provide a continuous means of generating immunoregulation that is convenient, active at lower doses without toxicity, effective if given before the onset of clinical Type I diabetes or early in the disease course and provided enhanced efficacy via unique and potent immunoregulatory circuits originating in the gut associated lymphoid tissue [51].

Acknowledgements. This research was conducted in whole by the Clayton Foundation for Research.

\section{References}

1. Laface D, Peck A (1989) Reciprocal allogeneic bone marrow transplantation between NOD mice and diabetes-nonsusceptible mice associated with transfer and prevention of autoimmune diabetes. Diabetes 38: 894-901

2. Castano L, Eisenbarth G (1990) Type I diabetes: A chronic autoimmune disease of human, mouse, and rat. Annu Rev Immunol 18: 647-679

3. Atkinson M, Maclaren N (1990) What causes diabetes? Sci Am 7: 62-71

4. Leiter E, Serreze D (1993) Antigen presenting cells and the immunogenetics of autoimmune diabetes in NOD mice. Reg Immunology 4: 263-273

5. Lampeter E, Homberg M, Quabeck K et al. (1993) Transfer of insulin dependent diabetes between HLA-identical siblings by bone marrow transplant. Lancet 341: 1243-1244

6. Brod SA, Burns DH (1994) Suppression of relapsing experimental allergic encephalomyelitis in the $\mathrm{SJL} / \mathrm{J}$ mouse by oral administration of type I interferons. Neurology 44: 1144-1148

7. Brod SA, Khan M, Pappolla M (1995) Oral administration of human or murine IFN-a suppresses relapses and modifies adoptive transfer in experimental autoimmune encephalomyelitis. J Neuroimmunol 58: 61-69

8. Brod S, Kerman R, Nelson L et al. (1997) Ingested IFN- $\alpha$ has biological effects in humans. Multiple Sclerosis - Clinical and Laboratory Research 3: 1-7

9. Serreze D, Leiter E (1994) Genetic and pathogenic basis of autoimmune diabetes in NOD mice. Curr Opin Immunol 6: 900-906

10. Hanafusa T, Miyagawa J-i, Nakajima H, Tomita K, Kuwajima M, Matsuzawa Y, Tarui S (1994) The NOD mouse. Diab Res Clin Prac 24(Suppl):S307-S311

11. Wicker L, Todd J, Petersen L (1995) Genetic control of autoimmune diabetes in the NOD mouse. Annu Rev Immunol 13: 179-200

12. McFarland H (1996) Complexities in the treatment of autoimmune disease. Science 274: 2037-2038

13. Liblau RS, Singer SM, McDevitt HO (1995) Th1 and Th2 CD4 + T cells in the pathogenesis of organ-specific autoimmune diseases. Immunol Today 16: 34-38 
14. Brod S, Khan M (1996) Oral administration of murine IFN$\alpha$ is more effective than parenteral administration in the suppression of relapses in EAE. J Autoimmunity 9: 11-20

15. Miller B, Appel M, O'Neil J, Wicker L (1988) Both the Lyt$2+$ and L3T4 + T cell subsets are required for the transfer of diabetes in nonobese diabetic mice. J Immunol 140: 52-58

16. Shimada A, Charlton B, Tayloredwards C, Fathman C (1996) Beta-cell destruction may be a late consequence of the autoimmune process in nonobese diabetic mice. Diabetes 45: 1063-1067

17. Asano M, Kohanawa M, Minagawa T, Nakane A (1996) Reciprocal action of interferon-gamma and interleukin-4 promote granulomatous inflammation induced by Rhodococcus aurantiacus in mice. Immunol 88: 394-399

18. Mu H, Sewell W (1994) Regulation of DTH and IgE responses by IL-4 and IFN-gamma in immunized mice given pertussis toxin. Immunology 83: 639-645

19. Chensue $S$, Warmington $K$, Ruth J, Lincoln $P$, and Kunkel S (1994) Cross-regulatory role of interferon-gamma (IFNgamma), IL-4 and IL-10 in schistosome egg granuloma formation: in vivo regulation of Th activity and inflammation. Clin Exp Immunol 98: 395-400

20. Suk S, Somers S, Erickson K (1993) Regulation of murine macrophage function by IL-4: IL-4 and IFN-gamma differentially regulate macrophage tumoricidal activation. Immunol 80: 617-624

21. Rapoport M, Jaramillo A, Zipris D et al. (1993) Interleukin 4 reverses $\mathrm{T}$ cell proliferative unresponsiveness and prevents the onset of diabetes in nonobese diabetic mice. $\mathrm{J}$ Exp Med 178: 87-89

22. Faust A, Rothe H, Schade U, Lampeter E, Kolb H (1996) Primary nonfunction of islet grafts in autoimmune diabetic nonobese diabetic mice is prevented by treatment with interleukin-4 and interleukin-10. Transplantation 62: 648-652

23. Mueller R, Krahl T, Sarvetnick N (1996) Pancreatic expression of IL-4 abrogates insulinitis and autoimmune diabetes in nonobese diabetic (NOD) mice. J Exp Med 184: 1093-1099

24. Pennline K, Roque-Gaffney E, Monahan M (1993) Recombinant human IL-10 prevents the onset of diabetes in the NOD mouse. Clin Immunol Immunopath 71: 169-175

25. Zheng X, Steele A, Hancock W et al (1997) A noncytolytic IL-10/Fc fusion protein prevents diabetes, blocks autoimmunity, and promotes suppressor phenomena in NOD mice. J Immunol 158: 4507-4513

26. Healey D, Arden S, Chandler P, Hutton J, Cooke A (1995) In vivo and in vitro specificity of CD $4+$ Th1 and Th2 cells derived from the spleens of diabetic NOD mice. J Clin Invest 95: 2979-2985

27. Rabinovitch A, Sorensen O, Suarez-Pinson W, Power R, Rajotte R, Bleackley R (1994 a) Analysis of mRNA expression in syngeneic islet grafts of NOD mice: IL-2 and IFN- $\gamma$ mRNA expression correlate with graft rejection and IL-10 with graft survival. Diabetologia 37: 833-837

28. Pilstrom B, Bjork L, Bohme J (1995) Demonstration of a Th1 cytokine profile in the late phase of NOD insulinitis. Cytokine 7: 806-814

29. Sarvetnick N, Liggitt D, Pitts S, Hansen S, Stewart T (1988) IDDM induced in transgenic mice by ectopic expression of class II MHC and interferon gamma. Cell 52: 773-782

30. Nicoletti F, Meroni P, Landolfo S et al. (1990) Prevention of diabetes in $\mathrm{BB} /$ Wor rats treated with antibodies to IFN $-\gamma$. Lancet 336: 319

31. Sarvetnick N, Shizuru J, Liggitt D et al. (1990) Loss of pancreatic islet tolerance induced by b cell expression of interferon- $\gamma$. Nature 346: 844-847
32. Campbell I, Kay T, Oxbrow L, and Harrison L (1991) Essential role for interferon $\mathrm{g}$ and interleukin 6 in autoimmune insulin-dependent diabetes in NOD/Wehi mice. J Clin Invest 87: 739-742

33. Debray-Sachs M, Carnaud C, Boitard C, Cohen H, Gresser I, Bedossa P, Bach J-F (1991) Prevention of diabetes in NOD mice treated with antibody to IFN $-\gamma$. J Autoimmunity $4: 237-248$

34. Foulis A, McGill M, Farquharson M (1991) Insulitis in type 1 IDDM in man: macrophages, lymphocytes, and IFN- $\gamma$ containing cells. J Pathol 164: 97-103

35. Balachov KE, Khoury S, Hafler D, Weiner HL (1995) Inhibition of T cell responses by activated human CD8 + T cells is mediated by IFN-gamma and is defective in chronic progressive multiple sclerosis. J Clin Invest 95: 2711-2719

36. Pauels H-G, Austrup F, Becker C, Schmitt E, Rude E, Kolsch E (1992) Lymphokine profile and activation profile of two unrelated antogen- or idiotype-specific T suppressor cell clones. Eur J Immunol 22: 1961-1966

37. Foulis A, Farquharson M, Meager A (1987) Immunoreactive IFN-a in insulin secreting b cells in type 1 IDDM. Lancet ii2: $1423-1427$

38. Huang X, Yuan J, Goddard A et al (1995) Interferon expression in the pancreas of patients with type I diabetes. Diabetes 44: 658-664

39. Stewart T, Hultgren B, Huang X, Pitts-Meek S, Hully J, MacLachlan $\mathrm{N}$ et al. (1993) Induction of type 1 diabetes by interferon- $\alpha$ in transgenic mice. Science 260: 1942-1945

40. Cantell K, Pyhala L (1973) Circulating interferon in rabbits after administration by different routes. J Gen Virol 20: 97-104

41. Bocci V, Naldini A, Corresdeschi F, Lencioni E (1985) Colorectal administration of human interferon- $\alpha$. Int $\mathbf{J}$ Pharmacokinet 24: 109-114

42. Bocci V (1991) Absorption of cytokines via the oropharyngeal associated lymphoid tissues - Does an unorthodox route improve the therapeutic index of interferon. Clin Pharmacokinet 21: 411-417

43. Fleischmann WR, Koren S, Fleischmann CM (1992) Oral administered interferons exert their white cell suppressive effects via a novel mechanism. Proc Soc Exp Biol Med 201: 199-207

44. Gibson DM, Cotler S, Spiegel HE, Colburn WA (1985) Pharmacokinetics of recombinant leucocyte A interferon following various routes and modes of administration to the dog. J Interferon Res 5: 403-408

45. Wills RJ, Spiegel HE, Soike KF (1984) Pharmacokinetics of recombinant leucocyte A interferon following IV infusion and bolus, IM, and PO administration to african green monkeys. J Interferon Res 4: 399-409

46. Witt PJ, Goldstein D, Storer BE, Grossberg SE, Flashner M, Colby CB, Borden EC (1992) Absense of biological effects of orally administered interferon- $\beta_{\text {ser }} \mathrm{J}$ Interferon Res 12: 411-413

47. Blalock JE, Baron S (1977) Interferon induced transfer of viral resistance between animal cells. Nature 269: 422-425

48. Butcher EC (1986) The regulation of lymphocyte traffic. Curr Topics Microbiol Immunol 128: 85-122

49. Butcher E, Picker L (1996) Lymphocyte homing and homeostasis. Science 272: 60-66

50. Bowman M, Leiter E, Atkinson M (1994) Prevention of diabetes in NOD mouse: implications for therapeutic intervention in human disease. Immunol Today 15: 115-120

51. Brod S (1997) Gut Response: Therapy with ingested immunoactive proteins. Arch Neurol 54: 1300-1302 